Acta Poetica 28 (1-2)

PRIMAVERA-OTOÑO

2007

\title{
Walter Benjamin: el coleccionismo como gesto filosófico
}

\author{
Silvana Rabinovich
}

Walter Benjamin dedicó varios textos a la figura del coleccionista, sin embargo, el gesto de la colección no se reduce a ser un tema de análisis entre otros, sino que imprime el carácter de su filosofía. Se tratará de abordar el coleccionismo como gesto filosófico, como ejercicio de memoria preñado de porvenir. En la sensible pluma de Benjamin, lectura y escritura en tanto ejercicios de coleccionista se traducen en promesa de justicia.

Walter Benjamin devoted various texts to the figure of the collector, nevertheless the gesture of the collector is not reduced to be a kind of analysis, but it leaves a trace of its philosophical character. We will try to approach collectionism as a philosophical gesture, as an exercise of memory filled with future. In Benjamin's texts, reading and writing as exercises of a collector are translated into a promise of justice. 

Acta Poetica 28 (1-2)

PRIMAVERA-OTOÑO

2007

Silvana Rabinovich

IIFL, UNAM

\section{Walter Benjamin: el coleccionismo como gesto filosófico}

¡Qué dicha la del coleccionista, la del hombre con tiempo!

Benjamin, "Desempacando mi biblioteca"

"Pero ¿qué tiene que ver el coleccionista con el filósofo?" Se preguntarán, no sin razón, algunos. ¿Qué extravagancia es ésta de asociar al sustantivo "gesto" (y no antes "pensamiento") con el calificativo "filosófico"? ¿Acaso se está insinuando que el más elevado arte de la abstracción está tocado por la mímica?

\section{En torno al gesto en filosofía}

[...] el gesto era para Kafka sin duda lo más inabarcable. Cada uno de ellos significaba de por sí un telón, o más aún, un drama. [...] Kafka [...] retira los soportes tradicionales del ademán para quedarse con un objeto de reflexión interminable. ${ }^{1}$

Benjamin supo leer en Kafka al gesto como objeto ("interminable") del pensamiento. En este trabajo, trataremos de pen-

${ }^{1}$ Walter Benjamin, Iluminaciones IV, Madrid, Taurus, 1999, pp. 144-145. 
sarlo - a través de Benjamin — en tanto sujeto, esto es, el gesto como aquello que piensa en nosotros, o la forma misma del pensamiento.

Marcel Jousse, autor de la Anthropologie du geste, ha investigado exhaustivamente la inherencia del gesto - como corolario de la mimesis - en el lenguaje, en la escritura, en la cultura. El jesuita sostiene que el esqueleto no es más que "un perchero (portemanteau) de hombre, un porta-gestos. Antes de fabricar herramientas, prolongaciones de sus gestos, el Anthropos ha modelado su gesto". ${ }^{2}$ Ahora bien, el autor aclara que no se trata de un ademán humano metafórico. "El Gesto es la energía viviente que propulsa este conjunto global que es el Anthropos: vita in gestu". En este sentido, y en consonancia con Aristóteles (Poética IV 2), el ser humano se define como animal mimético, como alguien que vuelve a poner en escena (rejoue) — cada vez de manera singular_ "mimemas" que le llegaron de otros. A partir de esto, las ideas se definen como la reproducción consciente de gestos, de mimemas recibidos (que serían unidades gestuales con sentido), dentro del marco de una ritmo-mímica que caracterizaría a la interacción humana. Lo mismo vale para la palabra oral y escrita, la escritura misma es abordada como sombras gestuales. Tal vez no sea tan heroico concebir al ser humano desde esta característica que guarda cierto tono simiesco; sin embargo, habría que pensar que las posibilidades del cuerpo y del ritmo amplían el horizonte filosófico. Las potencialidades del sentido se multiplican a partir del protagonismo de los sentidos en el pensamiento. Estas intuiciones no eran ajenas a Walter Benjamin, quien en su texto de 1935 "Problemas de sociología del lenguaje" menciona las investigaciones del "padre jesuita Marcel Jousse" (OC III 38), y que dos años antes, en "La enseñanza de lo

\footnotetext{
${ }^{2}$ Marcel Jousse, Anthropologie du geste, Paris, Gallimard, 1974, p. 50.
} 
semejante" (1933) entendía al lenguaje como la más elevada aplicación de la facultad mimética.

Desde esta perspectiva, es posible intentar el ejercicio de leer la escritura de los filósofos, también, como un conjunto de gestos generadores de significación (no olvidemos que “gesto" viene del latín ${ }^{3}$ gestus, que, además de movimiento o ademán, significa administración, procuración y manejo. Gero puede indicar: llevar sobre sí o consigo, conducir, mostrar, presentar, portarse, administrar, gobernar). Así, podríamos entender el "gesto filosófico" también como aquello que se lleva consigo a través de la escritura, aquello que se muestra en el pensamiento y refleja una manera de portarse.

Siguiendo estos sentidos, podemos decir que es frecuente encontrar en ciertos filósofos un gesto sobresaliente, característico de su escritura: una conducta de pensamiento, una manera de moverse, de portar y mostrar sus ademanes reflexivos, una forma particular de presentarse que tiene resonancias en ciertas artes y oficios. Para dar algunos ejemplos, se me ocurre que Kant podría ser un filósofo-arquitecto, Hegel un juez de la Suprema Corte de Justicia, Deleuze un alquimista y orfebre, Spinoza un bordador, Nietzsche un agricultor (y a la vez un mago), Heidegger un guardabosques, Rosenzweig un antropólogo forense, Bachelard un poeta, Heráclito un bailarín, Parménides un fotógrafo (o editor de cine), Sócrates un maestro disidente, Platón un dramaturgo, Aristóteles un estadista, Diógenes de Sínope un performancero (y padre de la resistencia creativa), Arendt una inmigrante ilegal, Levinas un maestro talmúdico, Buber un inspirador del mayo francés, Derrida un inventor y Foucault un zahorí. Prefiero no pensar en los policías, soldados o mercenarios, o en los funcionarios de la filosofía en general. Dentro de esta (como todas, arbitraria) clasificación, Benjamin aparecería como un filósofo-coleccionista.

\footnotetext{
${ }^{3}$ Datos tomados de Raimundo de Miguel, Nuevo diccionario latino-español etimológico, Madrid, Visor Libros, 2000.
} 
Aclaro que no pretendo reducir el complejo pensamiento de cada filósofo a un gesto o a una conducta que se transparenta en la escritura (eso equivaldría a caricaturizarlo y no es la intención del presente trabajo); sino ensayar otra lectura diferente, menos apegada a la fe en la estructura binaria del signo, a la intención del autor o a su contexto. Se trata de un cambio de perspectiva en el acto de leer que permita abordar la escritura en su dimensión escénica, dando aliento a la palabra del otro. Es allí donde la letra en su dictado deja percibir el ritmo y el mimema, entonces el cuerpo del lector se descubre danzando (Las danzas varían: puede ser tango, capoeira, la de los voladores de Papantla o hasta sorprenderse envuelto en un rito vudú).

\section{El tiempo del coleccionista y el tiempo del filósofo}

El coleccionismo es un fenómeno originario del estudio: el estudiante colecciona saber ${ }^{4}$

Benjamin, el lector, además de libros, colecciona citas, objetos de reflexión, y como todo coleccionista elabora un modesto catálogo. Como en toda buena colección, los objetos se dan cita en ella de manera libertina, burlando al supuesto ordenador. El catálogo de la colección funge como el marido que sospecha que su mujer — una belle de jour — trabaja en la casa de citas, ${ }^{5}$ y que su destino es ser ignorado. Entonces se queda afuera de la colección (desde allí tiene la ilusión de dominarla), el cónyuge no pasa del vestíbulo y en ese lugar imagina fotogramas de los encuentros e intercambios entre los protagonistas del lupanar de las ideas. Tal vez por eso Benjamin haya descrito

\footnotetext{
${ }^{4}$ Walter Benjamin, Libro de los pasajes, Madrid, Akal, 2005, p. 228.

${ }^{5}$ Un poco como Pierre, el marido de Sévérine en la película Belle de jour, dirigida por Luis Buñuel.
} 
varias características comunes entre los libros y las prostitutas, como por ejemplo, que ambos circulan en casas públicas para estudiantes. Y en cuanto a la vivencia del tiempo:

II. Los libros y las prostitutas entrecruzan el tiempo. Dominan la noche como el día y el día como la noche.

III. Nadie nota en los libros y en las prostitutas que los minutos les son preciosos. Sólo al intimar un poco más con ellos, se advierte cuánta prisa tienen. No dejan de calcular mientras nosotros nos adentramos en ellos. ${ }^{6}$

Si, como dice Benjamin en el epígrafe escogido, el coleccionista es un hombre con tiempo, esto vale para el filósofocoleccionista. ¡Y cuánta razón tiene este filósofo-con-tiempo cuando dice que los libros tienen prisa! Quién lo hubiera dicho de ellos, tan quietitos y con apariencia de sumisos... Cuando el lector cierra el libro, éste se entrega arrebatadamente al primero que fije su atención en él: en la biblioteca impera una suerte de biblio-ninfomanía. A este ritmo sincopado vive el filósofo coleccionador (y el estudiante también), sin embargo, cuando imagina que por fin logró domesticar (casar / cazar) al saber de colección, es que en realidad devino funcionario... Perfcipit ${ }^{7}$ gesto de colección, íncipit academia...

Pero volvamos a la escena anterior, la del filósofo loco de amor que desea rescatar a su sabiduría prostituida y esta vez se vale de una amiga: la memoria en la pluma de Bergson.

En la conclusión de Materia y memoria, Bergson explica que la percepción es una función del tiempo. Si viviéramos - podríamos decir - algunas cosas con calma, otras con rapidez, siguiendo otro ritmo, no habría nada 'consistente' para nosotros, sino que todo sucedería ante nuestros ojos como si nos asaltara de improviso. Pero eso es lo que le ocurre al gran co-

\footnotetext{
${ }^{6}$ Walter Benjamin, Dirección única, Madrid, Alfaguara, 1987, p. 47.

${ }^{7}$ Una vez más agradezco a Patricia Villaseñor su iluminadora ayuda en latín.
} 
leccionista con las cosas. Le asaltan de improviso. El hecho de perseguirlas y dar con ellas, el cambio que opera en todas las piezas una pieza nueva que aparece: todo ello le muestra sus cosas en perpetuo oleaje. Aquí se contemplan los pasajes de París como si fueran adquisiciones en manos de un coleccionista. (En el fondo, se puede decir que el coleccionista vive un fragmento de vida onírica. Pues también en el sueño el ritmo de la percepción y de lo que se vive cambia de tal modo que todo - incluso lo que en apariencia es más neutral- nos asalta de improviso, nos afecta. Para entender a fondo los pasajes, los sumergimos en el nivel onírico más profundo, y hablamos de ellos como si nos hubieran asaltado de improviso). ${ }^{8}$

Explícitamente, Benjamin refiere a los "pasajes" de París, pero esto nos tienta a leer arquitectónicamente ciertos pasajes de escritura, leer — como en los sueños- también en el sentido de pasar de un lugar al otro, de un sujeto al otro, de un mundo al otro. Esta cita describe un ritmo de lectura impredecible, el estado de excepción como regla, ${ }^{9}$ el sobresalto: fragilidad del filósofo coleccionista, del estudiante distraído, paseantes (flâneurs) desnudos por las páginas, materia onírica en carne viva. En esa desnudez del flâneur de los libros impera el tacto y ya no la vista. ${ }^{10}$ Esto no es un defecto en la lectura, tal vez sea el único sentido veraz de la investigación: sin duda es necesario planear el camino a seguir, pero si la vista quedara fijada en el método, la teleología conjuraría la sorpresa y el sobresalto capaces de erizar la piel. La hegemonía metódica anestesia al investigador y cancela la posibilidad de descubrir,

\footnotetext{
${ }^{8}$ Walter Benjamin, Libro de los pasajes, p. 224

9 Cf. Walter Benjamin, "Tesis de filosofía de la historia", en Angelus Novus, Barcelona, Edhasa, 1971.

10 "La propiedad y el tener están subordinados a lo táctil, y se encuentran en relativa oposición a lo óptico. Los coleccionistas son hombres con instinto táctil. Últimamente, por lo demás, con la retirada del naturalismo ha acabado la primacía de lo óptico que imperó en el siglo anterior. Flâneur. El flâneur, óptico; el coleccionista, táctil”. Walter Benjamin, Libro de los pasajes, p. 225.
} 
de aprender, esto es: de ser asaltado por el objeto para quedar sujetado a él. Por eso la memoria involuntaria e incluso la asociación salvaje de las ideas son el gesto característico de lectura del filósofo coleccionador, mientras que la memoria voluntaria, al modo de Sísifo, trabaja en el catálogo:

Una especie de desorden productivo es el canon de la memoria involuntaria, y también del coleccionista. [...] La memoria voluntaria, por el contrario, es un registro que dota al objeto de un número de orden bajo el que éste desaparece [...]. ${ }^{11}$

En el filósofo coleccionista ambas memorias se alternan, disienten y copulan generando un pensamiento que es un enjambre de potencialidades, de bifurcaciones posibles.

\section{Exilio y redención en el coleccionismo}

Quisiera aventurar una posible y puntual lectura escénica del filósofo-coleccionista haciendo alusión — casi tangencial- a dos películas: Una vida iluminada ${ }^{12}$ y Los cosechadores y yo. ${ }^{13}$

En cuanto a la primera, no voy a detenerme a juzgar los detalles fílmicos ni sus imprecisiones históricas, ${ }^{14}$ la abordaré en tanto ficción veraz, como una hagadah que (evocando a Benjamin sobre Kafka) antepone la transmisibilidad a la verdad. Coleccionista compulsivo, Jonathan Safran Foer anda por la vida provisto de bolsitas de plástico con cierre (de esas que se usan para conservar alimentos), presto a rescatar cualquier objeto del olvido. Rompiendo con la rutina, la bolsita sale de

${ }^{11}$ Walter Benjamin, Libro de los pasajes, p. 229.

12 "Everything is illuminated" (2005), dirigida por Liev Schreiber y basada en la novela de Jonathan Safran Foer del mismo nombre.

13 "Les glaneurs et la glaneuse" (2000) de Agnès Varda.

${ }^{14}$ Agradezco a Tatiana Bubnova sus valiosas precisiones al respecto. 
la cocina para operar el rescate sacando al objeto de contexto y destinándolo a la abigarrada (y algo caótica) pared de los recuerdos. El anillo hallado en Trachimbrod (Ucrania), encontrará su lugar más seguro junto a la foto de su abuelo Safran y no muy lejos de la dentadura postiza de su abuela, un poco más alejado de un memorable preservativo que con celo guardó. Una vez en Ucrania, y luego de "una búsqueda muy rígida", encuentra a una anciana que dice ser ella misma la aldea. (Las cajas que encuentra en Trachimbrod, clasificadas prolijamente por esta viejita que lo recibe, recuerdan a las cajas de galletas exhibidas por Christian Boltanski, ${ }^{15}$ y la pared evoca las colecciones de este artista.) Los contenedores de alimentos (cajas de galletas del artista, bolsitas sandwicheras en el personaje de la película) parecen estar destinados a atesorar el fulgor de la memoria revelada en objetos que han asaltado a los coleccionistas (ellos buscan, pero la intuición de la búsqueda inicia con la conciencia de la ignorancia de aquello pretérito que ha de venir por asalto). El hallazgo (presentado benjaminianamente en el film como "iluminación") encandila y transporta, cambia de manera radical el presente y el futuro, produciendo una constelación inesperada que deja entrever la inconmensurable generosidad del pasado.

Porque la actitud de un coleccionista hacia sus posesiones se deriva de un sentimiento de responsabilidad del dueño hacia su propiedad. Ésta es, en el más alto sentido, la actitud de un heredero, el rasgo más distintivo de una colección siempre será su transmisibilidad. ${ }^{16}$

\footnotetext{
15 "Boîtes à biscuits datées contenant des petits objets de Christian Boltanski", vista de la instalación de la exhibición "Local I", Galerie Daniel Templon, París, 1970. Agradezco a Laura Pomerantz el dato y las imágenes.

${ }^{16}$ Walter Benjamin, "Desemapacando mi biblioteca: una charla sobre los coleccionistas de libros", en Claudia Kerik (ed.), En torno a Walter Benjamin, México, UAM, 1993, p. 21.
} 
Los libros —en tanto herencia- aparecen iluminando el momento actual y el porvenir de dos maneras: por una parte el relato de la anciana que recuerda a Baruj (el bendito) que iba a la biblioteca y siempre andaba con un libro bajo el brazo (que no leía); este personaje se une con Safran, el abuelo muerto cuyo nombre en hebreo significa "bibliotecario"; tanto Jonathan Safran (que en la lengua de la Biblia podría significar "Dios ha dado un bibliotecario") como Alex —el nieto de Baruj- escriben cada uno por su lado esta historia.

¿Cómo procede el coleccionista?

Al coleccionar, lo decisivo es que el objeto sea liberado de todas sus funciones originales para entrar en la más íntima relación pensable con sus semejantes. Esta relación es diametralmente opuesta a la utilidad, y figura bajo la extraña categoría de la compleción. ¿Qué es esta ‘compleción'? Es el grandioso intento de superar la completa irracionalidad de su mera presencia integrándolo en un nuevo sistema histórico creado particularmente: la colección. Y para el verdadero coleccionista cada cosa particular se convierte en una enciclopedia que contiene toda la ciencia de la época, del pasaje, de la industria y del propietario de quien proviene. La fascinación más profunda del coleccionista consiste en encerrar el objeto individual en un círculo mágico, congelándose éste mientras le atraviesa un último escalofrío (el escalofrío de ser adquirido). Todo lo recordado, pensado y sabido se convierte en el zócalo, marco, pedestal, precinto de su posesión. No hay que pensar que es al coleccionista al que resulta extraño el topos hyperuranios que según Platón alberga las inmutables imágenes originarias de las cosas. El coleccionista se pierde, cierto. Pero tiene la fuerza de levantarse de nuevo apoyándose en un junco, y, del mar de niebla que rodea su sentido, se eleva como una isla la pieza recién adquirida. - Coleccionar es una forma de recordar mediante la praxis y, de entre las manifestaciones profanas de la 'cercanía', la más concluyente. Por tanto, en cierto modo, el más pequeño acto de reflexión política hace época en 
el comercio de antigüedades. Estamos construyendo aquí un despertador que sacude el kitsch del siglo pasado, llamándolo 'a reunión'. ${ }^{17}$

La fina malla que separa al coleccionista del pepenador (del ropavejero) pasa por la redención (no exenta de su matiz político). Una especie de ciclotimia (mágica) que va desde la exquisitez de la colección hasta los hedores de la basura. El delirio de la colección se refleja claramente en un texto de Stephan Zweig sobre Balzac.

Las esperanzas son para este iluso, magníficamente insanable, siempre certidumbres de inmediato. Y así pone esta vez también el carro delante de los bueyes, o mejor dicho, delante del lugar vacío correspondiente a los bueyes. En 1845, Balzac no posee ni la casa ni el lugar donde erigirla; tampoco posee el dinero necesario para comprar el solar del nuevo edificio. Pero ya comienza a amueblar a toda marcha la casa inexistente. Le ha invadido una nueva manía: la del ropavejero. ${ }^{18}$

Si obtengo de Luis Felipe tres mil francos por la cómoda, estaré muy satisfecho: habré ganado 1650 francos. Y ésta es una pequeña base con la que seguiré vagando por el mundo de las cosas viejas, para aumentar nuestros tesoros. ${ }^{19}$

La capacidad del coleccionista de quitar de contexto a fin de redimir y crear una nueva constelación — a primera vista descabellada - es compartida por el pepenador. Claro que las intenciones son diferentes. Mientras la actitud del coleccionista es más bien contemplativa (y algo animista); la del trapero es más práctica (pero no por ello menos sublime). La película Les glaneurs et la glaneuse borda sobre esta frontera... De

\footnotetext{
17 Walter Benjamin, Libro de los pasajes, p. 223.

18 Stephan Zweig, Balzac, capítulo "Balzac, el coleccionista", trad. A. Gregori, Buenos Aires, Editorial Jackson de Ediciones Selectas, 1948, p. 365.

${ }^{19}$ Ibid., p. 371.
} 
pronto se ilumina la cita de Baudelaire escogida por Benjamin que dice: "Todas esas antiguallas tienen un valor moral". ${ }^{20}$ Por ejemplo, cuando se trata de recoger todas aquellas hortalizas que quedaron después de la cosecha, ${ }^{21}$ o de reciclar objetos útiles o simplemente de manifestar el desacuerdo con el derroche de una sociedad consumista que daña a la ecología, el pepenador asume una responsabilidad heterónoma y política para con los desechos. En su piel carga la falta y los excesos de la sociedad que lo margina, y busca reivindicar su propio lugar social detrítico a través del rescate de la basura. Tanto el coleccionista como el trapero son extremadamente sensibles a los objetos en exilio, así, en un gesto compartido redimen al objeto de su estado de dispersión para asignarle un marco diferente, junto a otros. El pepenador y el coleccionista generan sociedades (profanas "cercanías"), y evocan la dialéctica del príncipe y el mendigo. Al igual que en la tradición profética, la palabra tiene la potencia de la promesa: el exilio (galut) espera a la redención (gueulah) que se dice como "reunión de las diásporas" o "congregación de exilios" (kibbutz galuyot).

No exagero al decir que para el verdadero coleccionista la adquisición de un libro nuevo es el renacimiento de éste" [...] "Para el coleccionista, saben, la verdadera libertad de todos los libros está en algún lugar de sus libreros. ${ }^{22}$

\footnotetext{
${ }^{20}$ Walter Benjamin, Libro de los pasajes, p. 221.

${ }^{21}$ Y que el Levítico, y luego la ley, ordena dejar para "el pobre, el extranjero, el huérfano y la viuda".

${ }^{22}$ Walter Benjamin, “Desempacando mi biblioteca:..., pp. 15 y 18.
} 


\section{El gesto filosófico benjaminiano como promesa}

Toda pasión colinda con lo caótico, pero la pasión del coleccionista colinda con un caos de recuerdos.

Benjamin, "Desempacando mi biblioteca"

Para concluir, podemos decir que en el [filósofo] coleccionista, la memoria voluntaria —en un gesto onírico- se pone al servicio de la memoria involuntaria, se dispone para su espera. En este sentido, su palabra es promesa, ejercicio de paciencia, espera de un porvenir que asalta desde un pasado remoto, siempre extranjero. El filósofo marcado por el gesto de la colección tiene un estilo particular, sensible y a primera vista caótico. ${ }^{23}$ Quien lo lea, como debe prestar atención al gesto, está obligado a frenar el impulso de comprensión, a envolverse en una pasividad hiperestésica y en ella dejar que sea el texto quien lea al sujeto lector, se monte encima de él y lo conduzca. En un ejercicio de paciencia, el lector se vuelve el corcel cuyo jinete es la letra del otro. El texto redime al lector, que cobra vida en este encuentro. ${ }^{24}$

En 1940, Benjamin filosofa como coleccionista cuando (en sus "Tesis de filosofía de la historia") saca de contexto al materialismo histórico y al mesianismo, generando constelaciones impensadas que iluminan de una forma única el más oscuro de los presentes. La alegoría (de la primera y la novena tesis) es el gesto de escritura filosófica que acoge la fuerza prometedora de este pensamiento, su dimensión profética (en el sentido de exigencia de justicia y no de predicción).

\footnotetext{
23 "Porque, ¿qué otra cosa es esta colección sino un desorden al que se ha adaptado el hábito a tal grado que parece orden?", Benjamin, "Desempacando mi biblioteca: una charla sobre los coleccionistas de libros", en Claudia Kerik (ed.), En torno a Walter Benjamin, México, UAM, 1993.

24 "Porque dentro de él hay espíritus, o por lo menos pequeños genios, que se han encargado de que, para él -me refiero a un verdadero coleccionista, a un coleccionista como debe ser- la propiedad sea la relación más íntima que se pueda tener con los objetos. No es que cobren vida en él; es él quien vive en ellos" (Ibid., p. 22).
} 
En otro texto, Benjamin distingue a Eduard Fuchs entre los historiadores por su gesto coleccionista. La lectura benjaminiana del historiador engendró nuestra lectura del propio filósofo.

On voit à plus d'une reprise que la polémique, de même que la discussion, est étrangère à l'écrivain Fuchs. Aussi combatif qu'il puisse paraître, la dialectique éristique qui, suivant la définition de Hegel, 'épouse la force de l'adversaire pour l'anéantir de l'intérieur', ne se trouve pas dans l'arsenal de Fuchs. $^{25}$

Este comentario recuerda a Deleuze cuando dice que "la philosophie a horreur des discussions". El filósofo coleccionista rehúye del folclor agonístico de los congresos, de la impaciente esgrima oral y escrita, es un hombre con tiempo, un maestro de la paciencia presto a acoger el sobresalto. Por eso su palabra es promesa. Este aforismo de Kafka da aliento al gesto de paciencia, insinuando en él la promesa:

Existen dos pecados capitales del hombre de los que derivan todos los demás: la impaciencia y la inercia. A causa de la impaciencia fueron expulsados del Paraíso, a causa de la inercia no han regresado. Pero quizá sólo haya un pecado capital: la impaciencia. A causa de la impaciencia fueron expulsados, a causa de la impaciencia no regresan. ${ }^{26}$

\footnotetext{
${ }^{25}$ Walter Benjamin, "Eduard Fuchs, collectionneur et historien", OC, III, Paris, Gallimard, 2000, p. 193.

${ }^{26}$ Franz Kafka, Aforismos de Zürau, México, Sexto Piso, 2004, p. 3.
} 


\section{BIBLIOGRAFÍA}

Benjamin, Walter, “Tesis de filosofía de la historia", en Angelus Novus, Barcelona, Edhasa, 1971.

- Dirección única, Madrid, Alfaguara, 1987.

- "Desempacando mi biblioteca: una charla sobre los coleccionistas de libros", en Claudia Kerik (ed.), En torno a Walter Benjamin, México, UAM, 1993.

- Iluminaciones IV, Madrid, Taurus, 1999.

— "Eduard Fuchs, collectionneur et historien", OC, III, Paris, Gallimard, 2000.

— "Problèmes de la sociologie du langage", $O C$, III, Paris, Gallimard, 2000.

— Libro de los pasajes, Madrid, Akal, 2005.

Jousse, Marcel, Anthropologie du geste, Paris, Gallimard, 1974.

KafKa, Franz, Aforismos de Zürau, México, Sexto Piso, 2004.

Miguel, Raimundo de, Nuevo diccionario latino-español etimológico, Madrid, Visor Libros, 2000.

ZweIG, Stephan, Balzac (Trad. A. Gregori), Cap. "Balzac, el coleccionista", Buenos Aires, Editorial Jackson de Ediciones Selectas, 1948. 